\title{
AHP-based Evaluation of IoT-aided Stadium Information System
}

\author{
Qiang $\mathrm{Ye}^{1, *}$ and Shan $\mathrm{Gao}^{2}$ \\ ${ }^{I}$ Dept. Science of Sport and Health, Nanjing Sport Institute, Nanjing, 210014, P.R. China; ${ }^{2}$ Electronic Information \\ Institute, Nanjing College of Information Technology, Nanjing, 210046, P.R. China
}

\begin{abstract}
Internet of Things (IoT), a new information technology, has obviously prompted building management. For stadiums are symbol buildings of many cities, investments on their modern upgrade are sustainable and incredible. Any investment will be focused by the public. However, lacking decision-making methodology for judging the income makes it difficult for upgrade willing of stadium owners. This paper has proposed a conceptual model of IoT-aided stadium information system (SIS) basing Internet of Things (IoT). Using the Analytic Hierarchy Process (AHP), a Multi-Criteria Decision Making template was designed for comparing SIS with a conventional SIS that in use at the Nanjing Olympic Center of China. The results showed that IoT-aided SIS was more meaningful and efficient than conventional SIS. With IoT, SIS helps stadium and enlarge its functional capability for local community and provide potentiality for the sports market. As an experimental technology still in progress, the key for IoT-aided SIS is the typical applications that provide standard and reference for future following applications.
\end{abstract}

Keywords: Analytic hierarchy process, electronic sports records, internet of things, stadium information system.

\section{INTRODUCTION}

Modern stadiums are primarily venues for plays, concerts, and other issues. For economic and other benefits, including increasing use and tax income, many cities across the world consider stadium application in their strategic development plans [1]. While the goals of sports investment encourage people to come back to stadiums and participate more sports activities, such initiatives are potentially considered as economic boosts [2]. Scholarly works, which touched the technology impact on sports facilities, indicate that sports teams and their facilities promise a great deal for the city, while the economic returns on investments are questionable [3]. The key to this argument is the extent to which spending on sports-related activities replaces spending on existing goods and services. Technology innovation is acknowledged as a competitive solution.

Technology is used to grow consumer interest and increase funding for sports, improve the quality of sports, regulate sports, and better access to sporting experiences [4-7]. In many domains, technology may act as an engine for management innovations. Innovations that address preidentified needs have a greater capability to prompt sports facilities. To date, there are no adequate systems, services, or software in the sports facilities management area [8] that satisfy the needs outlined above. Further, sports facilities information systems have received comparatively little attention from researchers. Our apprehension of the framework of the sports facilities information system is nevertheless at a rudimentary level. It is yet unclear what new technological frameworks such as the Internet of Things (IoT) contribute to sports facilities information systems.
In addition, to the best of our knowledge, there are no attempts in the literature to develop a sports facilities information system as a theoretical construct and to operate it for use in empirical studies. This paper seeks to rectify this situation fairly. The purpose of this paper is to develop and define a conceptual model of IoT-aided stadium information system (SIS) as a theoretical construct. Then compared with the conventional SIS, advantages and disadvantages of IoTaided SIS are presented for sports facilities and managers who strive to offer high-quality services to their users.

\section{BACKGROUND}

\subsection{Scope and Scale of SIS}

Traditionally, SIS also was known as a direct digital control system, and was regarded as tools for maintaining and caring for public, private, and non-profit facilities used for sports, recreation, and leisure, in order to ensure safe and secure production and distribution of products and services to users [9]. As a fact, stadiums often were a public building in the community and it did not result in significant development. The provision of suitable, accessible, and readily available sports facilities underpinned participation in sports and physical activities and helped to deliver the socially and economically beneficial by-products that accrued to an active community. Therefore, rather than a tool only for facilities management, an SIS which focused on communities with specific development logics and successful action plans was served as a driver for human developments.

This further highlighted the SIS inclusiveness for sports as a core component of an imagined health system that maximized the economical consumption of public funds and promoted healthier life choices for all. Further, Sports was seen as a viable "treatment" in the prevention of a range of conditions and the promotion of better public health [10]. 
The health benefits of stadiums were alluring, and researchers did doubtless continue to add to the growing body of impressive evidence. To optimize the value of SIS in promoting communities to more physical activities, it made sense for sports development and health professionals to work together more systematically. Sports provided the impetus for sedentary people, often indisposed to structured exercise, to become active. It also did the very important work of sustaining activity for those who were already active. Recent governmental policy moves had opened the door for work in this area to progress, although greater explicit political endorsement was desired. Many highly innovative and successful initiatives already took advantage of the opportunities and provided by the link between sports and better health.

\subsection{Requirements for SIS with IoT}

The Internet of Things (IoT) referred to the interconnection of uniquely identifiable embedded computing-like devices within the existing Internet infrastructure, and it allowed information to be shared among systems that affect each other $[11,12]$. The Internet of Things promised vast opportunities, but it also posed challenges for businesses that sought to take action and realized tangible results as it seemed overwhelming, complicated and expensive. It was clear that the developments in information technologies had affected stadium management significantly, from simple information management purposes to complex community health promotion [13]. As a result, IoT inevitably influenced the structure of SIS. New interoperable SIS represented a dramatic change, either in design or in function, from simple to even the most complex systems. With the development of Wireless Sensor Networks (WSN), such as Radio Frequency Identification devices (RFID) and Data Mining, IoT would solve challenges step by step. Though developments of many IoT based systems were reported in relative fields, such design on SIS should be noticed and addressed on the extended functionality of future stadiums.

\subsubsection{Flexibility}

Stadiums provided with extra functions were identified from other buildings, and the investment proportions of stadium information systems in the total funding were relatively higher, approximately $4 \%$ to $5 \%$ [14]. Because stadium information systems primarily used during comprehensive sports games, and transferred to community use afterwards, many subsystems were commonly considered low-return or high-idle. In most cases, especially in the initial design of those small and medium stadiums, information systems were always neglected and not taken into account. This was no benefit of SIS development in the future. To avoid investments waste or to efficiently use investments, SIS must be flexible. Rather than a completely new design, the IoT-aided SIS was an amelioration and reintegration into the conventional SIS.

\subsubsection{Individual}

With the feature of individuation, high standards, and high-quality services, once they matched with technical systems, new market opportunities was obvious to sports management $[15,16]$. IoT made SIS more intelligent and smart, which managers utilized to wisely operate the stadium. They even analyzed the spending habits of a spectator so that they provided targeted paid services. Consequently, the SIS directly affected the efficiency and effectiveness of the management of the stadium. Finally, information value chains would attract more funds and investments into SIS, and would prompt stadium management to act.

\subsubsection{Knowledge}

Information was a special product in the market for it provided enough knowledge. Knowledge was the aggregation of related information that formed a set of expectations or rules [16] and provided a clearer apprehension of the aggregated information [17]. Information systems were prepared that permitted people to extend their own knowledge while also benefitted the organization [18]. Data mining was the hunt for knowledge within the data. The SIS collected sports data from a myriad of structured and unstructured sources. The process of extracting these data to useful and interesting sports knowledge was categorized by the techniques practiced. Stadiums were ideal sources for data mining and knowledge management approaches. This was one of the important development trends of stadiums with the background of a more intellectual society.

\subsubsection{Open}

An open platform meant that the standard was both more likely to be of a high quality and much more likely to become widely embraced. Open standards lowed entry barriers and encouraged competing implementations, which in turn tended to foster innovation and lower costs to the consumer. The sports facility had become the most important component in the sports marketing [19]. It assisted to make a market [20] for sports and health promotion related to stadiums, as well as SIS evolution and operational creativity. Stadiums highly opened at most to meet the requirements of groups, such as minors, seniors or those with disabilities, and propelled both of economic benefits and social benefits [21]. Many researchers had proven that sports well promoted public health, which was a potential value of the SIS.

\subsection{Conceptual Model Purposed}

As mentioned above, the primary purpose of IoT-aided SIS was to pay more attention to the community sports promotion, this goal was achieved via the IoT. In this paper, we identified a conceptual model for IoT-aided SIS which was approved by some experts in this field through group discussion.

A simplified model for investigating the ways the IoT technology enhanced stadium management was proposed in Fig. (1). In this model, it included three-level: hardware layer gathered the information of individuals and facilities in the stadium to promote the utilization and maximize the function of facilities; communication layer provided a platform for IoT-aided SIS to label the stadium with digitization, and reasonable integrated control was deployed according to the standards of information needs for effective usage of facilities; software layer sort and analyzed the resources in the stadium to provide open information services. WSN and its applications adequately built a flexible and open platform. 


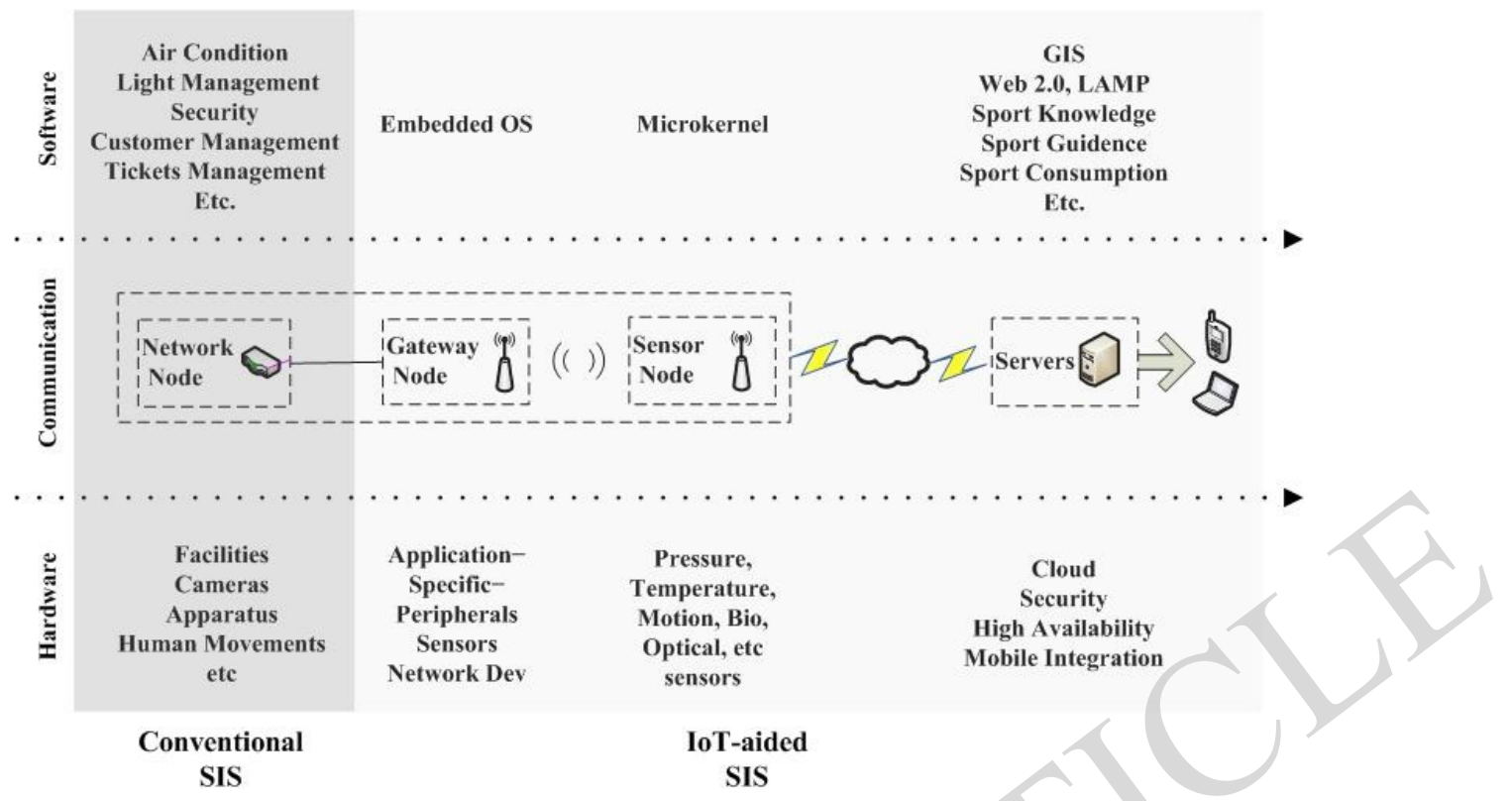

Fig. (1). The framework comparison of IoT-aided model SIS and conventional SIS.

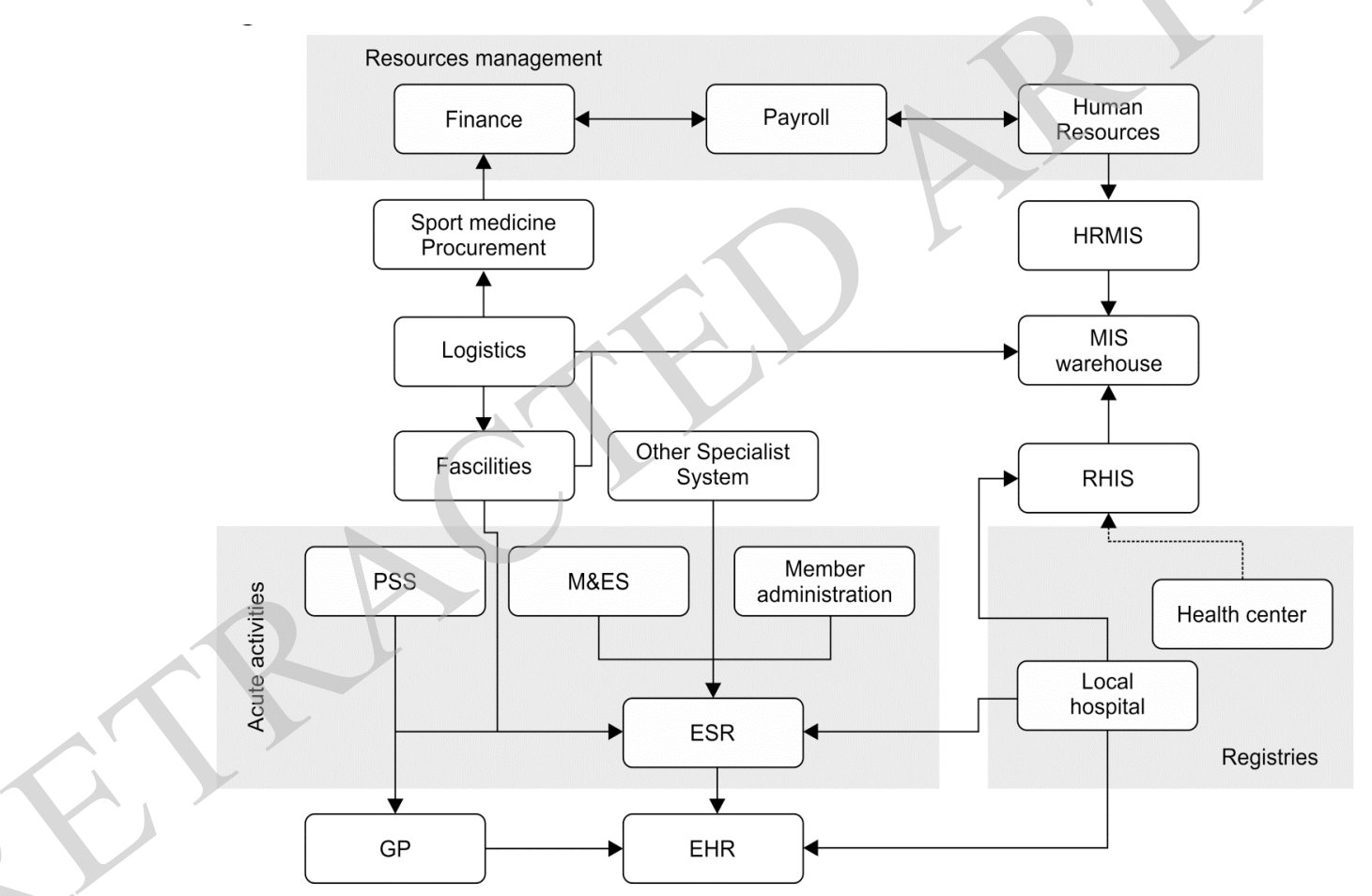

Fig. (2). The Workflow of the IoT-aided SIS. (ESR = electronic sports record, GP = general practitioner, HRMIS = human resources management information system, PSS = products sales system, M\&ES = measurement and evaluation system of sports science, MIS = management information system, RHIS = routine health information system, (S) EHR = (shared) electronic health record).

The sensor nodes, the gateways, or the server was omitted for specific components which adapted to best suit the application requirements and environmental conditions.

Moreover, workflow frameworks of this model reflected the characteristics of an organization as its members work through different stages in the cycle, providing conceptual guidelines on essential requirements and components at each stage, including key success drivers and indicators. The workflow of IoT-aided SIS focused on the provision of highquality services and accurately collecting data on users' physical activities Fig. (2).
At its core was the electronic sports record (ESR), which contained a series of SOAP message formats and the exchange of XML-formatted data. ESR was compatible with electronic health record (EHR) and adopted a similar data structure to it. ESR data came from a variety of sources. It interpreted and executed the established workflow and controlled all the components in the system to enact the whole process. The functionalities of the system were organized as several components corresponding to tasks.

After an initial deliberation, there was a need to develop a systematic evaluation model for SIS. It was necessary to 
Table 1. Criteria and their hypothesis.

\begin{tabular}{|c|c|c|c|}
\hline Goals & Measures & Identifications & Hypothesis \\
\hline 1 & Inputs & $\begin{array}{l}\text { - Cost of resources } \\
\text { - Attributes of resources } \\
\text { - Amount of resources }\end{array}$ & $\begin{array}{l}\text { - Facilities are in good maintenance } \\
\text { - Facilities are functioning } \\
\text { - Facilities are properly installed }\end{array}$ \\
\hline 2 & Usage & $\begin{array}{l}\text { - Amount of use } \\
\text { - Factors affecting use }\end{array}$ & $\begin{array}{l}\text { - Services are diversified } \\
\text { - Services are reasonable placed }\end{array}$ \\
\hline 3 & Domain & $\begin{array}{l}\text { - Target population } \\
\text { - Use and non-use population } \\
\text { - Information needs } \\
\text { - Number and attributes of sites }\end{array}$ & $\begin{array}{l}\text { - The community is encouraged to use the stadium } \\
\text { - All users are housed in a permanent framework } \\
\text { - Stadiums can support basic and extra information requirements } \\
\text { - There is sufficient information to meet various targets }\end{array}$ \\
\hline 4 & Outcomes & $\begin{array}{l}\text { - Time saved } \\
\text { - Improved quality of sport } \\
\text { - Improved productivity } \\
\text { - Improved timeliness of sport } \\
\text { - Value derived }\end{array}$ & $\begin{array}{l}\text { - Operating expenditures are sufficient } \\
\text { - Users get pleasure from participating in sporting activities } \\
\text { - Methods for addressing needs have been identified } \\
\text { - Sport requests are satisfied in a timely fashion } \\
\text { - Operating budget is stable and valuable }\end{array}$ \\
\hline 5 & Outputs & $\begin{array}{l}\text { - Amount of output } \\
\text { - Attributes of output }\end{array}$ & $\begin{array}{l}\text { - Information support improvements to any need } \\
\text { - Information support sports and health promotion }\end{array}$ \\
\hline
\end{tabular}

identify the factors that influenced the construction of SIS. Generic assessment measures include inputs, outputs, usage, outcomes, and domain measures [22]. The identified criteria were validated into a hierarchic structure of criteria, subcriteria and alternatives. The following detailed description was criteria for evaluating and developing an SIS:

Inputs: Provide high-quality sports, recreation, and leisure environments.

Output: Maintain facilities that best encourage and enable sports, recreation, and leisure practices.

Usage: Manage facilities effectively and efficiently in accordance with community use and sports management.

Outcomes: Ensure funds for stadium facilities are adequate and equitably allocated.

Domain: Offer data on community's sports and health situation to local health authorities, which are critically important for effective sports and health promotion.

Then, developing a detailed matrix (Table 1) help to define what specific data were incorporated into the SIS.

\section{METHODOLOGY}

In our work, the IoT-aided SIS described in this article were compared with the conventional SIS which used in the Nanjing Olympic Center. The Nanjing Olympic Center was established in 2005 and included several modern stadiums. The impacts of information technology had been a focus of research in recent years. A number of methods had been applied to evaluate their business performances. However, the applicability of these methods was often weakened by sophisticated mathematical models or limited attributes to facilitate operation in a real-world system design, especially when some attributes were not readily quantifiable, as well as difficult for managers to understand. The analytic hierarchy process (AHP) method directed how to determine the priority of a set of alternatives and the relative importance of attributes in a multi-criteria decision-making problem, and had been extensively discussed in various aspects [23]. However, it did not explain how to construct a specific objective structure relating to the management strategies and how to extract the proper criteria for evaluating how well the management requirements had been satisfied. Little research had been directed to address the subject of objective structures for assessing information systems. In one study conducted, a systematic procedure was proposed to construct the objective structure taking into account stadium management strategies and subsequently extract the associated attributes to evaluate IoT-aided SIS. This paper applied the AHP analytical framework to synthesize decision makers' tangible and intangible measures with respect to numerous competing objectives inherent in the information system and proved the worth of IoT-aided SIS through the group decision-making process. A decision hierarchy structured with criteria and alternative management options was extracted from Table $\mathbf{1}$. There were three layers in the decision hierarchy: The first layer described the overall system. The criteria and alternative options were in the second and third layers and identify the preferred management option given.

Eighteen experts agreed to participate in our study: six stadium managers, three persons from the Jiangsu Sports Information Center, and nine sports information researchers. An expert was a person whose skills, knowledge, and expertise were relevant to SIS and who has a minimum of 10 years of experience in this research or working field. Following the AHP methodology, paired comparisons of the alternatives for each attribute and the inter-attribute relative importance 
Table 2. Analysis of weights and sequence of criteria.

\begin{tabular}{|c|c|c|c|}
\hline Criteria & Weight & Sequence & Certified Value \\
\hline \hline Input & 0.285 & 2 & $\lambda_{\max }=3.054, \mathrm{CI}=0.0520$ \\
\hline Output & 0.050 & 5 & $\lambda_{\max }=2.000, \mathrm{CI}=0.0000$ \\
\hline Usage & 0.205 & 3 & $\lambda_{\max }=2.000, \mathrm{CI}=0.0000$ \\
\hline Outcome & 0.355 & 1 & $\lambda_{\max }=5.459, \mathrm{CI}=0.0990$ \\
\hline Domain & 0.105 & 4 & $\lambda_{\max }=4.500, \mathrm{CI}=0.0890$ \\
\hline
\end{tabular}

Table 3. Analysis of hierarchy weight, whole weight, and sequence for evaluation index.

\begin{tabular}{|c|c|c|c|}
\hline Evaluation index & $\begin{array}{c}\text { Hierarchy } \\
\text { Weight }\end{array}$ & $\begin{array}{l}\text { Whole } \\
\text { Weight }\end{array}$ & equ \\
\hline Amount of resources & 0.493 & 0.141 & 2 \\
\hline Cost of resources & 0.311 & 0.089 & 4 \\
\hline Attributes & 0.196 & 0.056 & 8 \\
\hline Amount of output & 0.667 & 0.033 & 10 \\
\hline Attributes of output & 0.333 & 0.017 & 14 \\
\hline Amount of use & 0.667 & 0.137 & 3 \\
\hline Factors affecting use & 0.333 & 0.068 & 6 \\
\hline Time saved & 0.113 & 0.040 & 9 \\
\hline Improved quality of sport & 0.503 & 0.178 & 1 \\
\hline Improved productivity & 0.244 & 0.087 & 5 \\
\hline Improved timeliness of sport & 0.072 & 0.026 & 11 \\
\hline Value derived & 0.065 & 0.023 & 12 \\
\hline Target population & 0.208 & 0.022 & 13 \\
\hline Use and non-use population & 0.062 & 0.007 & 16 \\
\hline Information needs & 0.627 & 0.066 & 7 \\
\hline Number and attributes of sites & 0.103 & 0.011 & 15 \\
\hline
\end{tabular}

were made and converted to a numerical scale. The software "Expert Choice" was then used to determine the normalized weights and synthesize the results. Throughout the evaluation procedure, the consistency index (CI) of each decision maker's paired comparison matrix was less than the threshold value 0.1 to ensure that the choices were consistent in assigning paired comparisons [24].

\section{RESULTS}

By means of literature study and questionnaires, we ascertained the essential functions of IoT-aided SIS. The 18 questionnaires from the experts were first incorporated. We then established a pairwise comparison matrix, and calculated the eigenvector, the largest eigenvalue, and the consistence index and ratio. In the end, we used the AHP framework to examine and compare the IoT-aided SIS with conventional SIS.
In gain to simply calculating results, the IoT-aided SIS provided a sort of additional modules, which influenced the choice of an alternative. Various criteria assessed these modules. Without discussing all the details of the two system alternatives, one identified tendencies about their target. From the sequence of criteria by weight (Table 2), the outcome has emerged as the most important factor in comparison (0.355), followed by input (0.285), usage (0.205), domain (0.105) and Output (0.050). The conventional SIS obviously targeted usage within the daily management of the stadium, whereas the IoT-aided SIS was more strategically and scientifically oriented to future business strategies.

To analyze the importance of sub-factors of the decision factors of IoT-aided SIS, weights of these sub-factors that give the relative importance with respect to their parent factors showed in Table 3 . 
The experts identified many systems from their experiences. They emphasized that the IoT-aided SIS should be fast and user-friendly for everyone. Satisfaction was the most important factor. "Improved quality of sports" emerges as the most significant sub-factor (weight of 0.178 ) followed by "Amount of resources" (weight of 0.141). They also thought it very significant to increase the possibility of management methods through specific customer services. Therefore, stadiums needed to incorporate efficient technological tools for real-time detection of user assessments. Through new technologies such as the IoT, the amount of resources increased and fulfilled the improvement requirement for user communication. Under the headline, the local priorities were presented for each criterion and each alternative, respectively. The corresponding weights were shown for each criterion in the same column. Finally, a sequence of alternatives was derived (Table 4).

Table 4. Results of AHP analysis.

\begin{tabular}{|c|c|c|}
\hline Alternatives & Geometric Mean & Certified Value \\
\hline \hline IoT-aided SIS & 0.701 & $\lambda_{\max }=5.282$ \\
\hline Conventional SIS & 0.299 & $\mathrm{CI}=0.063$ \\
\hline
\end{tabular}

According to quantity results from experts' decisions on multi-criteria, the IoT-aided SIS with IoT was better than the conventional SIS for sports facilities and managers who strived to offer high-quality services to their customers.

\section{DISCUSSION}

Based on a comprehensive review, the features of IoTaided SIS had been examined and identified. These gave an overview structure for sports managers without much knowledge of SIS. The AHP methodology was particularly useful for decision-making in a multi-criteria context. These decision-makers examined the strengths and weaknesses of both SIS, and sports managers could better understand the evaluation criteria in term of the functions of IoT-aided SIS.

The first finding was that data mining on ESR could help IoT-aided SIS swift from mere delivering of information to enabling users to develop lifelong sports spirits. With the speedy growth of science and technology, stadiums that involved users must provide mechanisms that allowed evaluation of the social impact and adoption of IoT solutions and applications [25]. Then, mass information contents could be sensed and provided to users. Information services should accurately meet information requirements [26]. This was important for stadiums because users require not only general and descriptive information, but also detailed and specialized information [27]. Various sports-related theories and styles incorporated into one stadium's environment to optimize the experience for users [28]. This included automated detection of situations when user behavior influenced the validity of collecting data, and also the provision of efficient multimodal mechanisms for user feedback. For example, in the monitoring of physical strength activities, the information demand could be even specific to concrete data or special data [29]. It was possible for data of ESR making Individual experiences along with meaningful group-based inter- actions, which encouraged users to be more effectively incorporated into physical activities [30]. It was meaningful that the functions of stadiums should be expanded to the fields of sports and health promotion.

The second finding was that IoT could help IoT-aided SIS offering more and better resources and services. The IoT-aided SIS involved not only sporting areas, but also nonsports-related auxiliary areas and elements such as equipment, facility maintenance, food services, emergency response, contractor services, employees, and users. The services of the conventional were currently not fully suitable for the consumer needs; however, accessibility could solve the problems of information gap between stadiums and consumers. The most important charactistic of the IoT was the capability of embracing "things" from the physical world on the Internet and facilitating interactions among them. The interface between the physical and digital worlds required the capacity for the digital world to sense the physical cosmos and to act on it. RFID was an automatic recognition technology that identified items and collected information about items without human intervention [31]. It operated using wireless technology and enabled item identification and data transmission without physical touch. Services offered by wireless sensor networks could be obtained through cooperation between these wireless sensor nodes, and classified into monitoring, tracking, alerting, and information "on-demand" [32].

The third finding was that the key to IoT-aided SIS development was typical application that could offer the standard and the reference for other applications. Further analysis of those lower sub-criteria, "use population", "number and attributes of sites" and "attributes of output", development of an IoT-aided SIS was still unexplored. For lack of typical applications as reference and standard, results implied the worries from experts on the invisibility of IoTaided SIS in a material environment. They have a vague idea of who will more benefit from IoT-aided SIS, what more advance functions IoT-aided SIS offers, and how extracted knowledge serves users. It was noted that there were some relevant strives in recent year. In 2011, Cisco Systems, Inc. and Real Madrid Football Club signed an agreement of transforming Bernabeu Stadium into an interactive stadium. It took full advantage of the variety of wireless networks, combined with multimedia screens, cells, iPads and other mobile devices. A corresponding information platform was also established to provide unique interactive informational experiences for the consultation. On March 2012, IBM declared that they would do an intellectualized reconstruction of Miami's Sun Life Stadium with the smart city concept. Stadium managers wisely operated the stadium. They even analyzed the spending habits of a spectator so that they provided targeted paid service. Consequently, the SIS directly affected the efficiency and effectiveness of the management of the stadium. Meanwhile, information value chains would attract more funds and investments into stadium information systems, and would prompt stadium management. Such applications would inevitably match technical system and properly guide information service design.

\section{CONCLUSION}

In this paper, a systemic approach was proposed to use AHP to assess a conceptual IoT-aided SIS. Although it was 
not exhaustive, the utility of the model was examined through observing its effect on the decision-making process in Comparing with conventional SIS. As a result, IoT-aided SIS an adequate environment that not only fulfilled the needs of owners/managers, but also served local community sports development. With the rise of strong interests in IoT-aided SIS, and IoT-aided SIS was assumed an important role in supporting the efficiency, reliability, and sustainability of stadiums. IoT-aided SIS would focus not only on digitization, intelligence, and versatility, but also its nature, that was the people-oriented community spirit.

\section{CONFLICT OF INTEREST}

The authors confirm that this article content has no conflict of interest.

\section{ACKNOWLEDGEMENTS}

This work is funded by the Social Science Foundation of the Jiangsu Higher Education Institutions of China (The Research on Development Goals system concept of Smart Sports and its controlling factors in Jiangsu Province), reference number 2012SJB890007.

\section{REFERENCES}

[1] D. Coates and B.R. Humphreys, "The effect of professional sports on earnings and employment in the services and retail sectors in US cities," Regional Science and Urban Economics, vol. 33, pp. 175198, 2003

[2] S. Trendafilova, S.N. Waller, R.B. Daniell, and J. McClendon, "Motor City" rebound? Sport as a catalyst to reviving downtown Detroit: A case study," City, Culture and Society, vol. 3, pp. 181187, 2012.

[3] C.A. Santo and G.C. Mildner, Sport and Public Policy: Social, Political, and Economic Perspectives, Human Kinetics, Chmpaign IL, 2010.

[4] S. Loland, "The ethics of performance-enhancing technology in sport," Journal of the Philosophy of Sport, vol. 36, pp. 152-161, 2009.

[5] T. Magdalinski, Sport, technology and body: the nature of performance, Routledge, London, 2008.

[6] A. Miah, S.B. Eassom, and C. Mitcham, Sport technology: history, philosophy and policy, Jai, 2002.

[7] J. Perl, M. Lames, and W.-D. Miethling, Information technology in sport: a handbook, Verlag Karl Hofmann, Schorndorf, 1997.

[8] L.E. Swayne, M. Dodds, and L. Ebooks, Corporation, Encyclopedia of sports management and marketing, Thousand Oaks, Calif: Sage Publications, Inc, 2011.

[9] E.C. Schwarz, S.A. Hall, S. Shibli, and L. Ebooks Corporation, Sport facility operations management: a global perspective, Oxford: Elsevier Butterworth-Hein, 2010.

[10] K. Hylton, Sports Development: Routledge, 2013.

[11] L. Atzori, A. Iera, and G. Morabito, "The internet of things: A survey," Computer Networks, vol. 54, pp. 2787-2805, 2010.

[12] C. Mukhopadhyay, Internet of Things: Challenges and Opportunities, Cham: Springer International Publishing, vol. 9, 2014.
[13] N. Wickramasinghe and, S. Kirn, "E-Health and the Future of Healthcare Information Systems," Business \& Information Systems Engineering, vol. 5, pp. 1-2, 2013.

[14] J.L. Li, J.P. Zhang, Z.L. Ma, D.Y. Wang and W. Lu, "Construction Information Management for the General Contractor of the National Stadium Project," In: Proceeding of Shanghai International Conference on Technology of Architecture and Structure, China, 2009.

[15] P. Guenzi, "Sport marketing and facility management: from stadiums to customer-based multipurpose leisure centres", In: D. Michel, Ed., Marketing and Football, Oxford: ButterworthHeinemann, 2007, pp. 130-162.

[16] M. Boisot, and A. Canals, "Data, information and knowledge: have we got it right?," Journal of Evolutionary Economics, vol. 14, pp. 43-67, 2004.

[17] P.E. Bierly III, E.H. Kessler, and E.W. Christensen, "Organizational learning, knowledge and wisdom," Journal of Organizational Change Management, vol. 13, pp. 595-618, 2000.

[18] M. Alavi, and D.E. Leidner, "Review: Knowledge management and knowledge management systems: Conceptual foundations and research issues," MIS Quarterly, pp. 107-136, 2001.

[19] D. Shilbury, H. Westerbeek, S.P. Quick, D.C. Funk, and A. Karg, Strategic sport marketing, Sydney: Allen \& Unwin, 2014.

[20] J. Bonander, and S. Gates, "Public health in an era of personal health records: opportunities for innovation and new partnerships," Journal of Medical Internet Research, vol. 12, no. 3, p. e33, 2010.

[21] R.A. Baade, and R.F. Dye, "An analysis of the economic rationale for public subsidization of sports stadiums," The Annals of Regional Science, vol. 22, pp. 37-47, 1988.

[22] M.J. Menou, Measuring the impact of information on development, Ottawa: International Development Research Centre, 1993.

[23] C.-C. Wei, C.-F. Chien, and M.-J.J. Wang, "An AHP-based approach to ERP system selection," International Journal of Production Economics, vol. 96, pp. 47-62, 2005.

[24] T.L. Saaty, and L.G. Vargas, Models, methods, concepts \& applications of the analytic hierarchy process, Springer, vol.1, 2001

[25] C.P. Cano and P.Q. Cano, "Human resources management and its impact on innovation performance in companies", International Journal of Technology Management, vol. 35, pp. 11-28, 2006.

[26] R. Ladhari, "Developing e-service quality scales: a literature review", Journal of Retailing and Consumer Services, vol. 17, pp. 464-477, 2010.

[27] P. Fremantle, S. Weerawarana, and R. Khalaf, "Enterprise services", Communications of the ACM, vol. 45, pp. 77-82, 2002.

[28] A. Edwards, and G. Finger, "eLearning and Sport Management: Hyperpedagogy Possibilities", Sport Management Review, vol. 10, pp. 191-208, 2007.

[29] D.E. Herlea Damian, C.M. Jonker, J. Treur, and N.J.E. Wijngaards, "Integration of behavioural requirements specification within compositional knowledge engineering", Knowledge-Based Systems, vol. 18, pp. 353-365, 2005.

[30] L. Yang, G. Su, and H. Yuan, "Design Principles of Integrated Information Platform for Emergency Responses: the case of 2008 Beijing Olympic Games", Information systems research, vol. 23 , pp. 761-786, 2012.

[31] R. Pateriya, and S. Sharma, "The evolution of RFID security and privacy: a research survey," In: Communication Systems and Network Technologies (CSNT), 2011 International Conference on, 2011, pp. 115-119.

[32] R. Shorey, A. Ananda, M.C. Chan, and W.T. Ooi, Mobile, wireless, and sensor networks: technology, applications, and future directions, Wiley-Interscience, 2006. 